\title{
EMERGENCY NURSES' DECISIONS REGARDING FREQUENCY AND NATURE OF VITAL SIGN ASSESSMENT
}

\section{RUNNING HEAD: EMERGENCY NURSES’ VITAL SIGN DECISIONS}

\section{AUTHORS}

Name:

Katherine Lambe

Qualifications:

$R N, B N$, MNursPrac

Affiliation:

School of Nursing and Midwifery, Deakin University

Nursing and Midwifery Education and Strategy, Monash

Health

Address:

c/- Deakin University, Geelong, Victoria, Australia, 3125.

Email:

k.lambe@deakin.edu.au

Telephone:

+61430855229

Name:

Professor Judy Currey

Qualifications:

$R N, B N($ Hons $) P h D$

Affiliation:

School of Nursing and Midwifery and Centre for Quality and

Patient Safety Research, Deakin University

Address:

c/- Deakin University, Geelong, Victoria, Australia, 3125.

Email:

judy.currey@deakin.edu.au

Telephone:

+61392446122

Name:

Professor Julie Considine

Qualifications:

RN PhD FACN, FFCENA

Affiliation:

School of Nursing and Midwifery and Centre for Quality and Patient Safety Research, Deakin University

Eastern Health - Deakin University Nursing \& Midwifery

Research Centre

Address:

c/- Deakin University, Geelong, Victoria, Australia, 3125

Email:

julie.considine@deakin.edu.au

Telephone:

+61392446127

This is the author manuscript accepted for publication and has undergone full peer review but has not been through the copyediting, typesetting, pagination and proofreading process, which may lead to differences between this version and the Version of Record. Please cite this article as doi: $10.1111 /$ jocn.13597

This article is protected by copyright. All rights reserved 


\section{AUTHORSHIP}

K Lambe (KL), J Considine (JCo) and J Currey (JCu) conceived and designed the study. KL secured funding. KL, JCo and JCu developed the study protocol and designed and tested the study instruments. KL collected the study data. KL, JCo and JCu analysed the data and prepared and approved the manuscript.

\section{FUNDING}

This study was generously supported by a Monash Health Nursing and Midwifery Research Scholarship

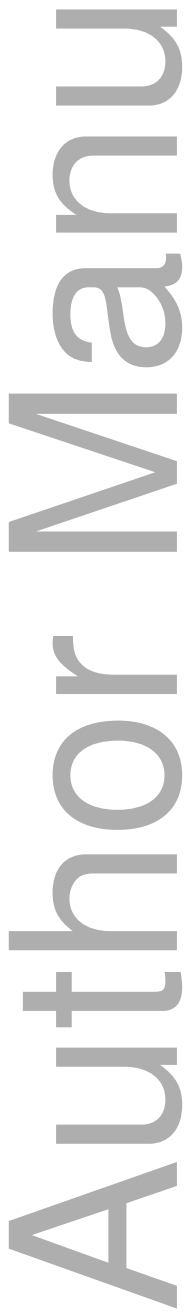


Article type

Original Article

EMERGENCY NURSES' DECISIONS REGARDING FREQUENCY AND NATURE OF VITAL SIGN ASSESSMENT

\section{ABSTRACT}

Aims and objectives

To explore the factors emergency nurses use to inform their decisions regarding frequency and nature of vital sign assessment.

\section{Background}

Research related to clinical deterioration and vital sign assessment in the emergency department is in its infancy. Studies to date have explored the frequency of vital sign assessment in the emergency department; however, there are no published studies that have examined factors that emergency nurses use to inform their decisions regarding frequency and nature of ongoing vital sign assessment.

\section{Design}

A prospective exploratory design was used. Data were collected using a survey consisting of eight patient vignettes.

\section{Methods}

The study was conducted in one emergency department in metropolitan Melbourne.

Participants were emergency nurses permanently employed at the study site.

\section{Results}

A $96 \%$ response rate was achieved $(n=47 / 49)$. The most common frequency of patient reassessment nominated by participants was 15 or 30 minutely, with an equal number of participants choosing these frequency intervals. Abnormality in initial vital sign parameters was the most common factor identified for choosing either a 15 or 30 minute assessment 
interval. Frequency of assessment decisions were influenced by years of emergency nursing experience in one vignette and level of postgraduate qualification in three vignettes. Heart rate, respiratory rate and blood pressure were all nominated by over $80 \%$ of participants as vital signs that participants considered important for reassessment. The frequency and nature of vital signs selected varied according to vignette content. There were significant negative correlations between assessment of conscious state and years of nursing experience and assessment of respiratory rate and years of emergency nursing experience. Level of postgraduate qualification did not influence selection of parameters for reassessment.

\section{Conclusion}

Emergency nurses are tailoring vital sign assessment to patients' clinical status and nurses are integrating known vital sign data into vital sign decision making.

\section{Relevance to clinical practice}

Accurate assessment and interpretation of vital sign data is fundamental to patient safety. Emergency nurses are responsible for the initial and ongoing assessment of undiagnosed or undifferentiated patients. Prior to medical assessment, emergency nurses are solely responsible for patient assessment, escalation of care and implementation of interventions within nursing scope of practice.

Keywords: emergency nursing; emergency department; risk assessment; patient safety; vital signs; patient assessment; clinical deterioration

\section{Summary box - What does this paper contribute to the wider global community?}

- This study provides a foundational understanding of emergency nurses' decision making regarding the ongoing frequency and nature of vital sign assessment.

- Emergency nurses are tailoring vital sign assessment to patients' clinical status and integrating known vital sign data into decisions regarding ongoing frequency and nature of vital sign assessment

- Emergency nurses' decisions regarding the nature of vital sign assessment are supported by evidence of known predictors of in-hospital adverse events such as respiratory rate, heart rate and blood pressure abnormalities

EMERGENCY NURSES' DECISIONS REGARDING FREQUENCY AND NATURE OF VITAL SIGN ASSESSMENT 


\section{INTRODUCTION}

Research related to clinical deterioration and vital sign assessment in the emergency department (ED) is in its infancy. There is an increasing evidence base that vital sign abnormalities present during ED care increases risk of in-hospital mortality and unplanned ICU admission (Barfod et al. 2012, Considine et al. in press, Farley et al. 2010, Jones et al. 2006, Kennedy et al. 2010). Vital sign assessment is a core emergency nursing responsibility (Curtis et al. 2009, Munroe et al. 2013, Munroe et al. in press) and accurate assessment and interpretation of vital sign data is fundamental to patient safety (Considine \& Currey 2015). The patient safety imperatives of nursing assessment are even more important in the ED context as many patients are solely in the care of emergency nurses while waiting for medical assessment. Although there are a few published studies related to the frequency of vital sign assessment in the ED (Armstrong et al. 2008, Johnson et al. 2014, Miltner et al. 2014), emergency nurses' decisions regarding the frequency and nature of vital sign assessment are poorly understood.

\section{Background}

Recognising and responding to clinical deterioration is an important issue in healthcare, both internationally and in Australia (Bogossian et al. 2014, Jones et al. 2012). It is widely accepted that early recognition of, and response to, clinical deterioration can improve patient outcomes, largely by preventing high mortality events such as cardiac arrest and unplanned intensive care unit admissions (Hillman et al. 2002, Mitchell et al. 2010, Ong et al. 2013). Vital sign assessment is a key nursing responsibility and is a major component of emergency nursing practice. A lack of consistent monitoring of vital signs, or failure to understand observed changes in vital signs is a factor that impacts on clinicians' abilities to identify and respond to the deteriorating patient (Australian Commission on Safety and Quality in Health Care (ACSQHC) 2011).

The epidemiology of clinical deterioration in ED patients is an area of developing knowledge. Recent Australian studies show that the most common cause of deterioration in ED patients is tachypnoea, tachycardia and hypotension (Considine et al. in press, Considine et al. 2012, Considine et al. 2015, Hosking et al. 2014), Further, there is emerging evidence that vital sign abnormalities present during ED care increases risk of in-hospital mortality, unplanned ICU admission and rapid response team activations in patients admitted to hospital wards 
(Barfod et al. 2012, Considine et al. in press, Farley et al. 2010, Jones et al. 2006, Kennedy et al. 2010, Mora et al. 2016).

Despite the importance of accurate vital sign assessment and the role of emergency nurses in initial and going patient assessment, there are no published studies regarding vital sign assessment specific to the Australian ED context. Observations of clinical practice suggest that emergency nurses reassess the vital signs of their patients on an hourly basis, regardless of their presenting problem. In some cases frequency of vital sign assessment is tailored to the patient's clinical status but this process is clinician dependent, ad hoc and poorly understood. There are currently no published studies that examine factors that emergency nurses use to make decisions regarding the ongoing frequency and nature of vital sign assessment

Aim

The aim of this study was to identify factors that emergency nurses use to inform their decision making regarding frequency and nature of ongoing vital sign assessment.

\section{METHODS}

\section{Design}

A prospective exploratory design was used to explore factors nursing staff use to inform their decision making regarding the frequency and nature of ongoing vital sign assessment for ED patients. The study was approved by the Human Research and Ethics Committees at the study site (15232L) and Deakin University (2015-160).

\section{Setting}

The study was conducted in one ED in metropolitan Melbourne. The study site was a 22 bed ED that managed 54555 attendances from 1 January to 31 December 2014 (Monash Health 2014). The study site had two resuscitation cubicles, six cardiac monitored cubicles and 14 general cubicles without cardiac monitoring. In addition, there was a 4 bed paediatric short stay unit and a 12 bed adult short stay unit. At the time of the study the ED nursing workforce was comprised of 110 permanent, predominantly part time staff with varying years of experience and levels of qualification. The ED had 13 nursing staff on a morning shift, 14 nursing staff on an afternoon shift and 13 staff rostered to work the night shift. The 'fast 
track' clinic was staffed by two nursing shifts, one starting at 0900 hours and the other starting at 1700 hours.

\section{Sample}

A convenience sample of emergency nurses permanently employed in the ED at the study site took part in the study. Exclusion criteria were nursing staff not permanently employed in the $\mathrm{ED}$ at the study site and those on leave at the time of data collection. In Australia, there are two levels of nurse: enrolled nurses undertake a two year Diploma, and registered nurses undertake a three year Bachelor Degree. In order to specialise in Emergency Nursing, registered nurses then undertake a Graduate Certificate (one year University university-based study), Graduate Diploma (two years University university-based study) or Master of Nursing (three year University university-based study).

\section{Data collection}

Study data were collected using a survey. In the first section of the survey, participants provided demographic data (level of qualifications, years of nursing experience and years of emergency nursing experience). In the second section of the survey, participants were provided with eight different vignettes. Each vignette included an adult patient, and the presenting problems for each 'patient' were based on the eight most common presentations to the ED (Table 1). A deliberate decision was made to vary the ages of the adult 'patients' in order to investigate the possibility of age being a factor nursing staff use to decide frequency and nature of vital sign assessment. Following a brief description of the 'patient', participants were provided with initial triage assessment findings including vital signs. Vital sign abnormalities, where present, were based on known antecedents to clinical deterioration. Face and content validity of the survey was established with the use of an expert panel encompassing both nursing and medical staff experienced in emergency care practice and research.

Participants were asked to complete four questions relating to each vignette:

i) Based on the above information how frequently do you plan to initially reassess the patient. Participants were requested to choose one option only from the following six options; every 15 minutes, 30 minutes, hour, 2 hours, 4 hours or the option of documenting a different frequency 
i) What observations would you initially reassess? Participants were able to choose as many parameters as they felt necessary and given the options of respiratory rate, oxygen saturation, blood pressure, heart rate, temperature, Glasgow Coma Score, pain score and neurovascular observations.

ii) What factors have informed your initial decision regarding the frequency of vital sign reassessment you chose?

iii) What factors have informed the parameters you have selected to reassess? A deliberate decision was made to collect the study data using a survey with vignettes as all participants would be making decision based on the same information. Participants were requested to write their response to these latter two questions as free text. The surveys were presented to nursing staff during in-service education time which occurs during day and evening shift overlap. Five sessions were held allowing distribution of the survey to 49 nursing staff: a total of 47 nurses completed and returned the survey giving a response rate of $96 \%$.

\section{Data analysis}

Descriptive statistics were used to summarise the quantitative survey data. Correlations (Spearman's rho) were used to examine relationships between years of experience and frequency of assessment and frequency of selection of parameters for reassessment. Level of postgraduate qualification was coded as follows: $0=$ nil, $1=$ graduate certificate, $2=$ graduate diploma, $3=$ Master's degree and $4=\mathrm{PhD}$. Procedures for thematic analysis were based on the six steps as outlined by Braun and Clarke (Braun \& Clarke 2006): familiarising oneself with the data, generating initial codes, searching for themes, reviewing themes, defining and naming themes and producing the report.

\section{RESULTS}

\section{Participant characteristics.}

A total of 49 surveys were distributed and 47 surveys were returned giving a response rate of $96.0 \%$. Of the 47 participants, one was an enrolled nurse and the remainder were registered nurses. A Bachelor of Nursing degree was the highest qualification for 23 participants. There were 12 participants holding the qualification of Graduate Certificate, two participants with a Graduate Diploma and five participants with a Master's Degree. Participants had a median of 12 years' nursing experience (IQR $=6.5-18.4$ ) and a median of 5.5 years emergency nursing experience $(\mathrm{IQR}=2.0-9.8)$. 


\section{Frequency of vital sign assessment}

The frequency of vital sign assessment most commonly chosen by participants was 15 minutes $(34.2 \%, \mathrm{n}=124)$ and 30 minutes $(34.2 \%, \mathrm{n}=124)$. However there was variability between cases with 15 minutes the most common option selected for Cases 1, 5, and 7 and 30 minutes the most common option selected for Cases 3, 4, and 6. The frequency of vital sign assessment for each case is shown in Table 2. The relationship between frequency of vital sign assessment (as an ordinal scale of 15 minutes, 30 minutes, 1, 2 and 4 hours) and years of nursing and emergency nursing experience, and level of postgraduate qualification (as an original scale (none, Graduate Certificate, Graduate Diploma and Master's degree) were examined. There were no statistically significant correlations between years of nursing experience and frequency of vital sign assessment. The only statistically significant correlation between years of ED experience and frequency of vital sign assessment was a negative correlation $\left(r_{s}=-0.399, p=0.005\right)$ for Case 3 ( 75 year old male with shortness of breath) indicating that as years of ED experience increased, the intervals for vital sign reassessment in this case decreased. There were significant negative correlations between level of postgraduate qualification and frequency of vital sign assessment in Case 1 (45 year old male with abdominal pain; $r_{s}=-0.356, p=0.015$ ), Case 5 ( 72 year old female with chest pain; $\left.r_{s}=-0.323, p=0.030\right)$ and Case 7 (25 year old female with febrile illness; $r_{s}=-0.379$, $\mathrm{p}=0.010$ ). These negative correlations suggest that as the level of postgraduate qualification increased, the intervals for vital sign reassessment in this case decreased.

** Table 2 here

Participants were asked to describe, in free text, the factors that informed their decisions regarding how frequently vital signs should be assessed. The most common reasons cited for participants' decisions regarding the frequency of vital sign assessment are summarised in Table 3). The most common reasons reported for 15 minutely vital sign reassessment were abnormal vital signs in the initial case $(51.6 \%, \mathrm{n}=64 / 124)$ and moderate $(5 / 10)$ to severe pain $(8 / 10)(31.4 \%, n=39 / 124)$. Concern regarding potential diagnoses was evident in three cases and specifically concerns about cardiac causes of abdominal or chest pain and sepsis or overdose as a cause for undifferentiated febrile illness (29.0\%, $\mathrm{n}=36 / 124)$. Pale, cool and diaphoretic skin was reported in one case (Case 1) as a reason for 15 minutely vital sign reassessment $(16.1 \%, \mathrm{n}=20 / 124)$ and concerns regarding decreased Glasgow Coma Score and 
impact on airway patency was reported only in Case $7(15.5 \%, \mathrm{n}=19 / 124)$. The requirement of 30 minutely observations were abnormalities in the initial set of vital signs $(46.8 \%, \mathrm{n}=$ $58 / 124)$, increased work of breathing $(24.5 \%, \mathrm{n}=30 / 124)$ and risk of further deterioration $(14.5 \%, n=18 / 124)$.

The reason most commonly cited for hourly observations was the presence of normal vital signs in the initial case information $(50 \%, n=50 / 100)$. Low $(2 / 10)$ to moderate levels (4/10) of pain were reported as influencing the decision for hourly vital signs in $28 \%$ of cases $(n=28 / 100)$. Two hourly reassessment was nominated in $1.7 \%(n=6 / 362)$ of cases. The two hour frequency of vital sign assessment was nominated in by $2 \%$ of participants in Case 2 ( $\mathrm{n}=$ $1 / 47)$ and $11.6 \%$ of participants in Case $8(n=5 / 43)$. In relation to Case $8,60.0 \%(n=3 / 5)$ of participants cited stable vital signs as reasoning for this interval of reassessment. The other $40.0 \%(\mathrm{n}=2 / 5)$ of responses neglected to give a reason for this assessment frequency. Four hourly vital sign assessment was not nominated by any of the participants as a frequency of vital sign collection for any of the vignettes.

** Table 3 here

\section{Vitals sign parameters identified as requiring assessment}

Overall, heart rate $(85.9 \%, \mathrm{n}=317)$, respiratory rate $(84.6 \%, \mathrm{n}=312)$ and blood pressure $(82.1 \%, \mathrm{n}=303)$ were all nominated by over $80 \%$ of participants as vital signs that participants would reassess. Vascular observations were the least nominated observation, selected by $19.0 \%(n=70)$ of participants. Less than half of the participants nominated that they would reassess temperature $(48.0 \%, \mathrm{n}=177)$ and Glasgow Coma Score $(47.2 \%, \mathrm{n}=174)$. The vital sign parameters that participants identified as requiring reassessment are shown for each case in Table 4.

** Table 4 here

The vital signs identified as requiring reassessment were varied between cases. Vital sign abnormalities in the original 'patient' description was commonly reported by participants as the major factor influencing their choice to reassess specific parameters and was the case in $18.3 \%(57 / 312)$ of choices to reassess respiratory rate; $16.3 \%$ of cases to reassess oxygen saturation (46/282); $16.5 \%$ of choices to reassess blood pressure (50/303); $25.9 \%$ choices to 
reassess heart rate (82/317); and $10.2 \%$ of choices to reassess temperature (18/177). Altered conscious state in the original 'patient' description was reported to influence $12.6 \%$ of choices to reassess Glasgow Coma Score (22/174). Neurovascular observations were nominated for reassessment in 70 cases and the major reason for this choice was reported to be risk of further neurovascular compromise in $60 \%$ of cases (42/70). In the 229 cases where pain score was nominated as necessary for reassessment, risk of deterioration was reported as an influence on that choice in $8.3 \%$ of cases (19/229) and vital sign abnormalities in the original 'patient' description was reported to be an influence on $11.8 \%$ of cases $(27 / 229)$.

Participant's frequency of selecting individual parameters in each vignette (respiratory rate, oxygen saturation, heart rate, blood pressure, conscious state, temperature, neurovascular status and pain) were calculated across the eight vignettes. The median number of times participants selected each parameter across the eight cases was one for neurovascular status $(\mathrm{IQR}=1-2), 3$ for conscious state (IQR = 2-7), 3.5 for temperature (IQR 2-6.25), 5 for pain $(\mathrm{IQR}=4-6)$ and 7 for all values (respiratory rate and systolic blood pressure IQR 6-8; heart rate IQR = 6.75-8; oxygen saturation IQR = 5 - 7). There were statistically significant negative correlations between years of experience and frequency of selection of conscious state $\left(r_{s}=-0.359, p=0.021\right)$ and years of ED experience and frequency of selection of respiratory rate $\left(r_{s}=-0.334, p=0.035\right)$. There were no significant correlations between level of postgraduate qualification and frequency of selection of specific parameters for reassessment.

\section{DISCUSSION}

This study had two major findings. First, the most common frequency of vital sign assessment reported by participants was either 15 or 30 minutely. This is a markedly higher frequency of vital sign assessment than is currently being achieved in practice. A recent Australian study showed the frequency of vital sign assessment in ED patients ranges from a median of every 66 minutes for heart rate to 2 hours for Glasgow Coma Score (Lambe 2016). The discrepancy between hypothetical and actual vital sign assessment intervals result raises the possibility that staff are reporting idealised intervals of vital sign reassessment that are unachievable in clinical practice. Barriers to vital sign assessment on the general wards have been explored in the literature and reasons such as time constraints due to increasing workload and lack of appreciation of abnormal values have been identified (Mok et al. 
2015a). Crowding in the ED has been correlated with adverse outcomes such as delayed medication administration, delayed cardiac intervention and increased mortality rates (Johnson et al. 2014); however, barriers to emergency nurses undertaking vital sign assessment is an area that, to date, has not been examined.

The most common rationale noted for 15 and 30 minute frequency of reassessment was the presence of abnormal vital signs in the vignette. It is unclear why the same factor (abnormal vital signs), prompted some participants to choose a 15 minute frequency and others to choose a 30 minute frequency of reassessment. Decisions regarding frequency of vital sign assessment were largely unaffected by years of nursing or ED nursing experience. The level of postgraduate qualification had a significant negative correlation with frequency of vital sign assessment in three of the eight cases (Cases 1, 5 and 7); however, these cases represented patients of various ages and with disparate clinical conditions. These results reflect, in part, the results of research related to triage decision making that show factual knowledge to be more important than years of emergency nursing or triage experience in triage decision accuracy (Considine et al. 2007). The influence of nurse characteristics on other decisions in the emergency care context warrants further investigation.

Of the participants who chose a 15 minute frequency of vital sign reassessment for Case 7 (25 year old female with febrile illness), $61.3 \%(n=19 / 31)$ mentioned a specific concern with ongoing airway patency. It is encouraging to see that when a potential airway concern is present emergency nurses plan to reassess the situation frequently as airway patency is vital for ongoing life (Considine \& Currey 2015). Pain, although not the most common factor cited for choosing the 15 minute frequency of assessment was mentioned by $61.1 \%(n=22 / 36)$ of participants in Case 1 (45 year old male with abdominal pain) and 56.7\% ( $\mathrm{n}=17 / 30)$ of participants in Case 5 (72 year old female with chest pain). It is hypothesised that perhaps the pain levels and more specifically treatment of the pain lead participants to choose this frequency. Policy at the study site highlights that patients should be reassessed no longer than 15 minutes after the administration of an opioid, common treatment for both acute abdominal pain and chest pain (Monash Health 2015). The most common factor noted for reassessment of patients at an interval of 1 or 2 hours was the presence of normal vital signs. This finding suggests that emergency nurses acknowledge that initial normal vital signs could change and that reassessment remains important. 
Second, the most common rationale for participant's choice of vital sign parameters to reassess was abnormalities in that specific vital sign in the vignette. Heart rate, respiratory rate and blood pressure abnormalities were all nominated by over $80 \%$ of participants for reassessment in the vignettes. This is a reassuring finding, as tachycardia, tachypnoea and hypotension are all known predictors of in hospital adverse events (Barnaby et al. 2002, Bleyer et al. 2011, Burch et al. 2008, Goldhill \& McNarry 2004, Jones et al. 2006). More recent research has shown that tachypnoea, tachycardia and hypotension (meeting hospital Rapid Response System (RRS) activation criteria) present in ED increases odds that a patient will require a RRS activation within the first 72 hours of their inpatient stay (Considine et al. in press). More participants nominated respiratory rate as needing reassessment $(84.6 \%$, $n=312 / 369$ ) than oxygen saturation $76.4 \%, n=282 / 369$ ). Again, this is reassuring given the historical reports that respiratory rate was poorly documented (Cretikos et al. 2008), and finding that nurses have placed a higher reliance on oxygen saturation than respiratory rate (Mok et al. 2015b). Our results suggest that emergency nurses do in fact place a higher value on respiratory rate than oxygen saturation, suggesting that dissemination of earlier research findings and education are positively impacting nurses' clinical decision making.

Temperature $(48.0 \% \mathrm{n}=177 / 369)$ and Glasgow Coma Score $(47.2 \% \mathrm{n}=174 / 369)$ were nominated for reassessment in under half of the vignette responses. This finding is congruent with results of an Australian retrospective chart audit in which temperature and Glasgow Coma Score were shown to be reassessed less frequently than respiratory rate, oxygen saturation, blood pressure and heart rate (Lambe 2016). The possibility has been raised that nurses assess conscious state when interacting with patients but fail to document this assessment unless it is abnormal (Considine et al. 2016). Our study supports this possibility, because in Case 7 (the only vignette to present a patient with an altered Glasgow Coma Score) $100 \%(n=46 / 46)$ of participants nominated Glasgow Coma Score for reassessment. The reason for not reassessing temperature is not clear and is concerning. At the time of data collection, the monitoring of temperature as a sign of Systemic Inflammatory Response Syndrome (SIRS) and sepsis was guiding practice. If abnormal temperatures are not identified and treated in a timely manner, significant increases in patient mortality may result (Dellinger et al. 2013).

When choice of parameter selection for reassessment was examined, nurses with more years of nursing experience were less likely to select conscious state, nurses with more years of ED 
nursing experience were less likely to select respiratory rate and there were no significant correlations identified between level of postgraduate qualification and frequency of selection of specific parameters for reassessment. The reason for these findings is unclear. It may be argued that it is almost impossible to have a patient encounter without assessing conscious state so experienced nurses don't necessarily articulate conscious state assessment. It may also be argued as described previously, that the importance of respiratory rate as an indicator of clinical deterioration has been a key feature of clinical education programs over the last decade so this may explain why nurses with less experience in emergency nursing were more likely to select respiratory rate as a factor for reassessment (Cretikos et al. 2008).

Currently there is a lack of high quality evidence in the area of frequency of vital sign assessment, with current practices largely being based on tradition and expert opinion (Hands et al. 2013, Storm-Versloot et al. 2014). The Australian Commission on Safety and Quality in Health Care (2010) suggest that frequency of vital sign assessment should be determined by patient diagnosis. However, patients in ED often have no diagnosis for the majority of their episode of care (Curtis et al. 2009). To date there are no published studies that have examined the factors that emergency nurses use to inform their decision making regarding frequency and nature of ongoing vital sign assessment. There are also no published studies regarding the effect of nurse characteristics on vital sign assessment decisions in emergency care.

When interpreting the results of this study the following limitations need to be considered. Hypothetical patient scenarios were used in this study so how the study findings translate to real-world emergency care in unknown. As highlighted in methods, the use of written vignettes was to enable assessment of nurses' decisions based on the same information and therefore answer the research questions. In a real clinical setting, it would be expected that nurses' decisions would be different for different patients with specific clinical needs. Controlling for confounders and assessing the decisions of multiple nurses for one patient, although presenting a methodological challenge, warrants further consideration for future research. Participants in this study were self-selecting, which may raise issues of selection bias; however, the response rate was $96 \%$ so it is unlikely that the non-responder group influenced study results. There were a limited number of surveys not fully completed. From a possible 376 responses, only 14 vignettes contained no response to the question regarding frequency of vital sign reassessment, 7 vignettes contained no response to the nature of vital sign assessment. It is doubtful that this small amount of missing data would have impacted on 
the study results. Finally, it is possible that participant responses were influenced by perceptions of what was expected rather than a true reflection of their decision making process.

\section{CONCLUSIONS}

The aim of this study was to explore emergency nurses' assessment of patient vital signs. Accurate assessment and interpretation of vital sign data is fundamental to patient safety. Emergency nurses are faced with the additional challenge of being responsible for the assessment of undiagnosed or undifferentiated patients and are the sole care providers until medical assessment occurs. The results of this study demonstrate that in hypothetical scenarios, emergency nurses are tailoring vital sign assessment to patients' clinical status and integrating known vital sign data into their decision making regarding ongoing frequency and nature of vital sign assessment. Further research in real time emergency care is required to further our understanding of how patient and context factors influence emergency nurses' vital sign decisions.

\section{REFERENCES}

Armstrong B, Walthall H, Clancy M, Mullee M \& Simpson H (2008). Recording of vital signs in a district general hospital emergency department. Emergency Medicine Journa1 25, 799-802.

Australian Commission on Safety and Quality in Health Care (ACSQHC) (2010) National Consensus Statement: essential elements for recognising and responding to clinical deterioration. Australian Commission on Safety and Quality in Health Care, Sydney.

Retrieved 1 August 2016 from http://www.safetyandquality.gov.au/wpcontent/uploads/2012/01/national_consensus_statement.pdf.

Australian Commission on Safety and Quality in Health Care (ACSQHC) (2011) National Safety and Quality Health Service Standards. Australian Commission on Safety and Quality in Health Care, Sydney. Retrieved 1 August 2016 from http://www.safetyandquality.gov.au/publications/national-safety-and-quality-healthservice-standards/.

Barfod C, Lauritzen MMP, Danker JK, Sölétormos G, Forberg JL, Berlac PA, Lippert F, Lundstrøm LH, Antonsen K \& Lange KHW (2012). Abnormal vital signs are strong predictors for intensive care unit admission and in-hospital mortality in adults triaged 
in the emergency department-a prospective cohort study. Scandinavian Journal of Trauma, Resuscitation and Emergency Medicine 20, 1.

Barnaby D, Ferrick K, Kaplan D, Shah S, Bijur P \& Gallagher J (2002). Heart rate variability in emergency deartment patients with sepsis. Acaedemic Emergency Medicine 9, 661670.

Bleyer AJ, Vidya S, Russell GB, Jones CM, Sujata L, Daeihagh P \& Hire D (2011).

Longitudinal analysis of one million vital signs in patients in an academic medical center. Resuscitation 82, 1387-1392.

Bogossian F, Cooper S, Cant R, Beauchamp A, Porter J, Kain V, Bucknall T, Phillips NM \& First Act Research Team (2014). Undergraduate nursing students' performance in recognising and responding to sudden patient deterioration in high psychological fidelity simulated environments: an Australian multi-centre study. Nurse Education Today 34, 691-696.

Braun V \& Clarke V (2006). Using thematic analysis in psychology. Qualitative Research in Psychology 3, 77-101.

Burch VC, Tarr G \& Morroni C (2008). Modified early warning score predicts the need for hospital admission and inhospital mortality. Emergency Medicine Journal 25, 674678.

Considine J, Botti M \& Thomas S (2007). Do knowledge and experience have specific roles in triage decision-making? Academic Emergency Medicine 14, 722-726.

Considine J \& Currey J (2015). Ensuring a proactive, evidence-based, patient safety approach to patient assessment. Journal of Clinical Nursing 24, 300-307.

Considine J, Jones D, Pilcher D \& Currey J (in press). Patient physiological status during emergency care and rapid response team or cardiac arrest team activation during early hospital admission. European Journal of Emergency Medicine, available on line 06/02/2016 http://journals.lww.com/euro-emergencymed/toc/publishahead.

Considine J, Lucas E \& Wunderlich B (2012). The uptake of an early warning system in one Australian Emergency Department: a pilot study. Critical Care and Resuscitation 14, $135-141$.

Considine J, Rawet J \& Currey J (2015). The effect of a staged, emergency department specific, rapid response system on reporting of clinical deterioration. Australasian Emergency Nursing Journal 18, 218-226.

Considine J, Trotter C \& Currey J (2016). Nurses' documentation of physiological observations in three acute care settings. Journal of Clinical Nursing 25, 134-143. 
Cretikos MA, Bellomo R, Hillman K, Chen J, Finfer S \& Flabouris A (2008). Respiratory rate: the neglected vital sign. Medical Journal of Australia 188, 657-659.

Curtis K, Hoy S, Murphy M \& Lewis MJ (2009). The emergency nursing assessment process: A structured framework for a systematic approach. Australasian Emergency Nursing Journal 12, 130-136.

Dellinger RP, Levy MM, Rhodes A, Annane D, Gerlach H, Opal SM, Sevransky JE, Sprung CL, Douglas IS, Jaeschke R, Osborn TM, Nunnally ME, Townsend SR, Reinhart K, Kleinpell RM, Angus DC, Deutschman CS, Machado FR, Rubenfeld GD, Webb S, Beale RJ, Vincent J-L \& Moreno R (2013). Surviving Sepsis Campaign: International Guidelines for Management of Severe Sepsis and Septic Shock, 2012. Intensive Care Medicine 39, 165-228.

Farley H, Zubrow MT, Gies J, Kolm P, Mascioli S, Mahoney DD \& Weintraub WS (2010). Emergency department tachypnea predicts transfer to a higher level of care in the first 24 hours after ED admission. Academic Emergency Medicine 17, 718-722.

Goldhill DR \& McNarry AF (2004). Physiological Abnormalities in early warning scores are related to mortality in adult inpatients. British Journal of Anaesthesia 92, 882 -884.

Hands C, Reid E, Meredith P, Smith GB, Prytherch DR, Schmidt PE \& Featherstone PI (2013). Patterns in the recording of vital signs and early warning scores: compliance with a clinical escalation protocol. BMJ Quality \& Safety 22, 719-726.

Hillman KM, Bristow PJ, Chey T, Daffurn K, Jacques T, Norman SL, Bishop GF \& Simmons G (2002). Duration of life-threatening antecedents prior to intensive care admission. Intensive Care Medicine 28, 1629-1634.

Hosking J, Considine J \& Sands N (2014). Recognising clinical deterioration in Emergency Department patients. Australasian Emergency Nursing Journal 17, 59-67.

Johnson KD, Winkelman C, Burant CJ, Dolansky M \& Totten V (2014). The factors that affect the frequency of vital sign monitoring in the emergency department. Journal of Emergency Nursing 40, 27-35.

Jones AE, Yiannibas V, Johnson C \& Kline JA (2006). Emergency department hypotension predicts sudden unexpected in-hospital mortality: a prospective cohort study. Chest 130, 941-946.

Jones DA, Dunbar NJ \& Bellomo R (2012). Clinical deterioration in hospital inpatients: the need for another paradigm shift. The Medical Journal of Australia 196, 97-100.

Kennedy M, Joyce N, Howell MD, Lawrence Mottley J \& Shapiro NI (2010). Identifying infected emergency department patients admitted to the hospital ward at risk of 
clinical deterioration and intensive care unit transfer. Academic Emergency Medicine 17, 1080-1085.

Lambe K (2016) Vital Sign Assessment Decisions by Emergency Nurses. (unpublished) Master of Nursing Practice Thesis. School of Nursing and Midwifery, Deakin University, Geelong, Australia.

Miltner RS, Johnson KD \& Deierhoi R (2014). Exploring the frequency of blood pressure documentation in emergency departments. Journal of Nursing Scholarship 46, 98105

Mitchell IA, McKay H, Van Leuvan C, Berry R, McCutcheon C, Avard B, Slater N, Neeman T \& Lamberth P (2010). A prospective controlled trial of the effect of a multi-faceted intervention on early recognition and intervention in deteriorating hospital patients. Resuscitation 81, 658-666.

Mok W, Wang W, Cooper S, Ang EN \& Liaw SY (2015a). Attitudes towards vital signs monitoring in the detection of clinical deterioration: scale development and survey of ward nurses. International Journal for Quality in Health Care 27, 207-213.

Mok WQ, Wang W \& Liaw SY (2015b). Vital signs monitoring to detect patient deterioration: An integrative literature review. International Journal of Nursing Practice 21 Suppl 2, 91-98.

Monash Health (2014) Emergency Department Attendance Data. Monash Health, Clayton.

Monash Health (2015) Intravenous Opioids in the Management of Acute Pain in the Emergency Department. Monash Health, Clayton.

Mora JC, Schneider AG, Robbins R, Bailey M, Bebee B, Hsiao Y-FF, Considine J, Jones D \& Bellomo R (2016). Epidemiology of early Rapid Response Team activation after emergency department admission. Australasian Emergency Nursing Journal 19, 5461.

Munroe B, Curtis K, Considine J \& Buckley T (2013). The impact structured patient assessment frameworks have on patient care: an integrative review. Journal of clinical Nursing 22, 2991-3005.

Munroe B, Curtis K, Murphy M, Strachan L, Hardy J, Considine J, Wilson M, Ruperto K, Fethney J \& Buckley T (in press). A structured framework improves clinical patient assessment and non-technical skills of early career emergency nurses: a pre-post study using full immersion simulation. Journal of Clinical Nursing, available on line 03/05/2016. 
Ong ME, Goh K, Fook-Chong S, Haaland B, Wai KL, Koh ZX, Shahidah N \& Lin Z (2013). Heart rate variability risk score for prediction of acute cardiac complications in ED patients with chest pain. American Journal of Emergency Medicine 31, 1201-1207.

Storm-Versloot MN, Verweij L, Lucas C, Ludikhuize J, Goslings JC, Legemate DA \& Vermeulen H (2014). Clinical relevance of routinely measured vital signs in hospitalized patients: a systematic review. Journal of Nursing Scholarship 46, 39-49.

Table 1: Summary of vignette content

\begin{tabular}{l} 
Vignette \\
\hline 1 \\
45 year old male with central abdominal pain. He states that the pain has been \\
getting worse over the last $2-3$ days. He rates his pain currently as $8 / 10$ and \\
states it is sharp in nature. He is cool to touch and diaphoretic. He has no past \\
medical history. He has been triaged to Australian Triage Scale category 2. \\
80 year old female with 1 week of increasing upper right quadrant pain. She \\
rates her current pain severity as $2 / 10$. She reports vomiting for the last 3 days \\
and has vomited twice today before attending the ED, the vomit has been \\
yellow in colour. She reports normal bowel actions. \\
75 year old male with shortness of breath over the last 3 weeks. He is speaking \\
in short sentences and is using accessory when breathing. \\
26 year old male with 3 hours of increasing shortness of breath. He is speaking \\
to you in sentences and using accessory muscles for breathing. \\
72 year old female with 40 minutes of left sided chest pain, dull in nature, $5 / 10$ \\
and no radiation. She also reports shortness of breath, she is speaking in short \\
sentences and exhibits no additional signs of increased work of breathing. \\
66 year old female with 24 hour history of vomiting clear fluid. She denies \\
pain and has had no loose bowel actions. She has no past medical history and \\
takes no medications. \\
25 year old female with altered conscious state and changed behaviour. She \\
has a history of being an intravenous drug user but family report no drug use \\
for past 3 years. She is currently being treated for a urinary tract infection by \\
her local doctor. She is drowsy and her skin is hot to touch. \\
34 year old male who fell from his son's skate board onto his outstretched right \\
65
\end{tabular}


arm. There is an obvious deformity to his right forearm. He denies any loss of consciousness and has full recall of events. He rates his current pain 4/10, his neurovascular status is normal but he has decreased movement of his fingers due to pain

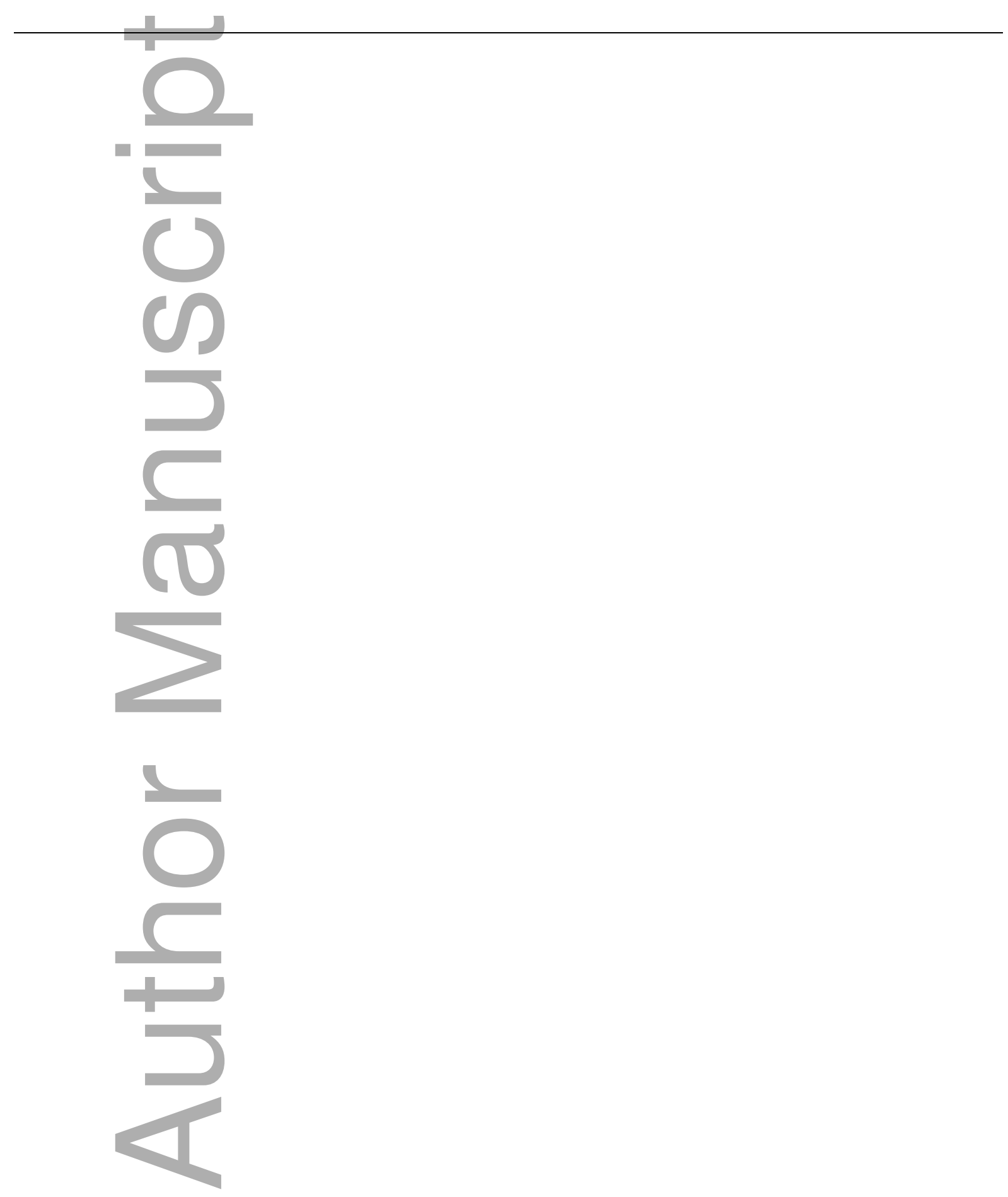




\begin{tabular}{|c|c|c|c|c|c|c|c|c|c|c|c|c|c|c|}
\hline \multirow{2}{*}{ ת } & \multicolumn{2}{|c|}{15 minutes } & \multicolumn{2}{|c|}{30 minutes } & \multicolumn{2}{|c|}{ Hourly } & \multicolumn{2}{|c|}{2 hourly } & \multicolumn{2}{|c|}{4 hourly } & \multicolumn{2}{|c|}{ Other } & \multicolumn{2}{|c|}{ Total } \\
\hline & $\mathbf{n}$ & $\%$ & $\mathbf{n}$ & $\%$ & $\mathbf{n}$ & $\%$ & $\mathbf{n}$ & $\%$ & $\mathbf{n}$ & $\%$ & $\mathbf{n}$ & $\%$ & $\mathbf{n}$ & $\%$ \\
\hline $\begin{array}{l}\text { Case } 1 \quad(n=46) \\
45 \text { year old male }\end{array}$ & 36 & 78.3 & 7 & 15.2 & 1 & 2.2 & 0 & 0.0 & 0 & 0.0 & 2 & 4.3 & 46 & 100 \\
\hline Case $2(n=47)$ & 0 & 0.0 & 4 & 8.5 & 42 & 89.4 & 1 & 2.1 & 0 & 0.0 & 0 & 0.0 & 47 & 100 \\
\hline 80 year old fem & & & & & & & & & & & & & & \\
\hline $\begin{array}{l}\text { Case } 3(n=45) \\
75 \text { year old male }\end{array}$ & 12 & 26.7 & 31 & 68.9 & 1 & 2.2 & 0 & 0.0 & 0 & 0.0 & 1 & 2.2 & 45 & 100 \\
\hline $\begin{array}{l}\text { Case } 4(n=46) \\
26 \text { year old male }\end{array}$ & 12 & 26.1 & 26 & 56.5 & 8 & 17.4 & 0 & 0.0 & 0 & 0.0 & 0 & 0.0 & 46 & 100 \\
\hline $\begin{array}{l}\text { Case } 5(\mathbf{n}=\mathbf{4 5}) \\
72 \text { year old fem }\end{array}$ & 30 & 66.7 & 9 & 20.0 & 4 & 8.9 & 0 & 0.0 & 0 & 0.0 & 2 & 4.4 & 45 & 100 \\
\hline $\begin{array}{l}\text { Case } 6(n=45) \\
66 \text { year old fem }\end{array}$ & 3 & 6.7 & 26 & 57.8 & 16 & 35.5 & 0 & 0.0 & 0 & 0.0 & 0 & 0.0 & 45 & 100 \\
\hline Case $7(n=45)$ & 31 & 68.9 & 10 & 22.2 & 1 & 2.2 & 0 & 0.0 & 0 & 0.0 & 3 & 6.7 & 45 & 100 \\
\hline $\begin{array}{l}25 \text { year old fem } \\
\text { Case } 8(n=43)\end{array}$ & 0 & 0.0 & 11 & 25.6 & 27 & 62.8 & 5 & 11.6 & 0 & 0.0 & 0 & 0.0 & 43 & 100 \\
\hline 34 year old male & & & & & & & & & & & & & & \\
\hline Total $(\mathrm{N}=362)$ & 124 & 34.2 & 124 & 34.2 & 100 & 27.7 & 6 & 1.7 & 0 & 0 & 8 & 2.2 & 362 & 100 \\
\hline
\end{tabular}

Table 3: Most common reasons selected when choosing frequency of vital sign assessment

This article is protected by copyright. All rights reserved 


\begin{tabular}{|c|c|c|c|c|c|c|c|c|}
\hline \multirow[b]{2}{*}{ Abnormalities in the initial set of vital signs } & \multicolumn{2}{|c|}{$\begin{array}{c}15 \text { minutes } \\
(\mathrm{n}=124)\end{array}$} & \multicolumn{2}{|c|}{$\begin{array}{c}30 \text { minutes } \\
(\mathrm{n}=124)\end{array}$} & \multicolumn{2}{|c|}{$\begin{array}{l}1 \text { hourly } \\
(n=100)\end{array}$} & \multicolumn{2}{|c|}{$\begin{array}{c}2 \text { hourly } \\
(n=5)\end{array}$} \\
\hline & 64 & 51.6 & 58 & 46.8 & 50 & 50.0 & & \\
\hline Pain scores $5 / 10$ to $8 / 10$ & 39 & 31.4 & & & & & & \\
\hline Pale, cool diaphoretic skin & 20 & 16.1 & & & & & & \\
\hline $\begin{array}{l}\text { Decreased Glasgow Coma score raising concerns } \\
\text { regarding airway patency }\end{array}$ & 19 & 15.5 & & & & & & \\
\hline Increased work of breathing & & & 30 & 24.5 & & & & \\
\hline Risk of further deterioration & & & 18 & 14.5 & & & & \\
\hline Pain scores $2 / 10$ to $4 / 10$ & & & & & 28 & 28.0 & & \\
\hline Initial set of vital signs were normal & & & & & & & 3 & 60.0 \\
\hline
\end{tabular}

Table 4: Parameters identified as needing reassessment per case

\begin{tabular}{|c|c|c|c|c|c|c|c|c|c|c|c|c|c|c|c|}
\hline \multirow{2}{*}{ (2) } & \multicolumn{2}{|c|}{$\begin{array}{l}\text { Respiratory } \\
\text { rate }\end{array}$} & \multicolumn{2}{|c|}{$\begin{array}{c}\text { Oxygen } \\
\text { saturation }\end{array}$} & \multicolumn{2}{|c|}{$\begin{array}{c}\text { Blood } \\
\text { pressure }\end{array}$} & \multicolumn{2}{|c|}{$\begin{array}{c}\text { Heart } \\
\text { rate }\end{array}$} & \multicolumn{2}{|c|}{ Temperature } & \multicolumn{2}{|c|}{$\begin{array}{c}\text { Glasgow } \\
\text { Coma } \\
\text { Score }\end{array}$} & \multicolumn{2}{|c|}{$\begin{array}{c}\text { Vascular } \\
\text { observations }\end{array}$} & \multirow[t]{2}{*}{$\begin{array}{l}\text { Pain } \\
\text { score }\end{array}$} \\
\hline & $\mathbf{n}$ & $\%$ & $\mathbf{n}$ & $\%$ & $\mathbf{n}$ & $\%$ & $\mathbf{n}$ & $\%$ & $\mathbf{n}$ & $\%$ & $\mathbf{n}$ & $\%$ & $\mathbf{n}$ & $\%$ & \\
\hline Case $1 \quad(n=47)$ & 39 & 82.9 & 27 & 57.4 & 47 & 100.0 & 46 & 97.9 & 26 & 55.3 & 26 & 55.3 & 9 & 19.1 & 43 \\
\hline
\end{tabular}

45 year old male with 


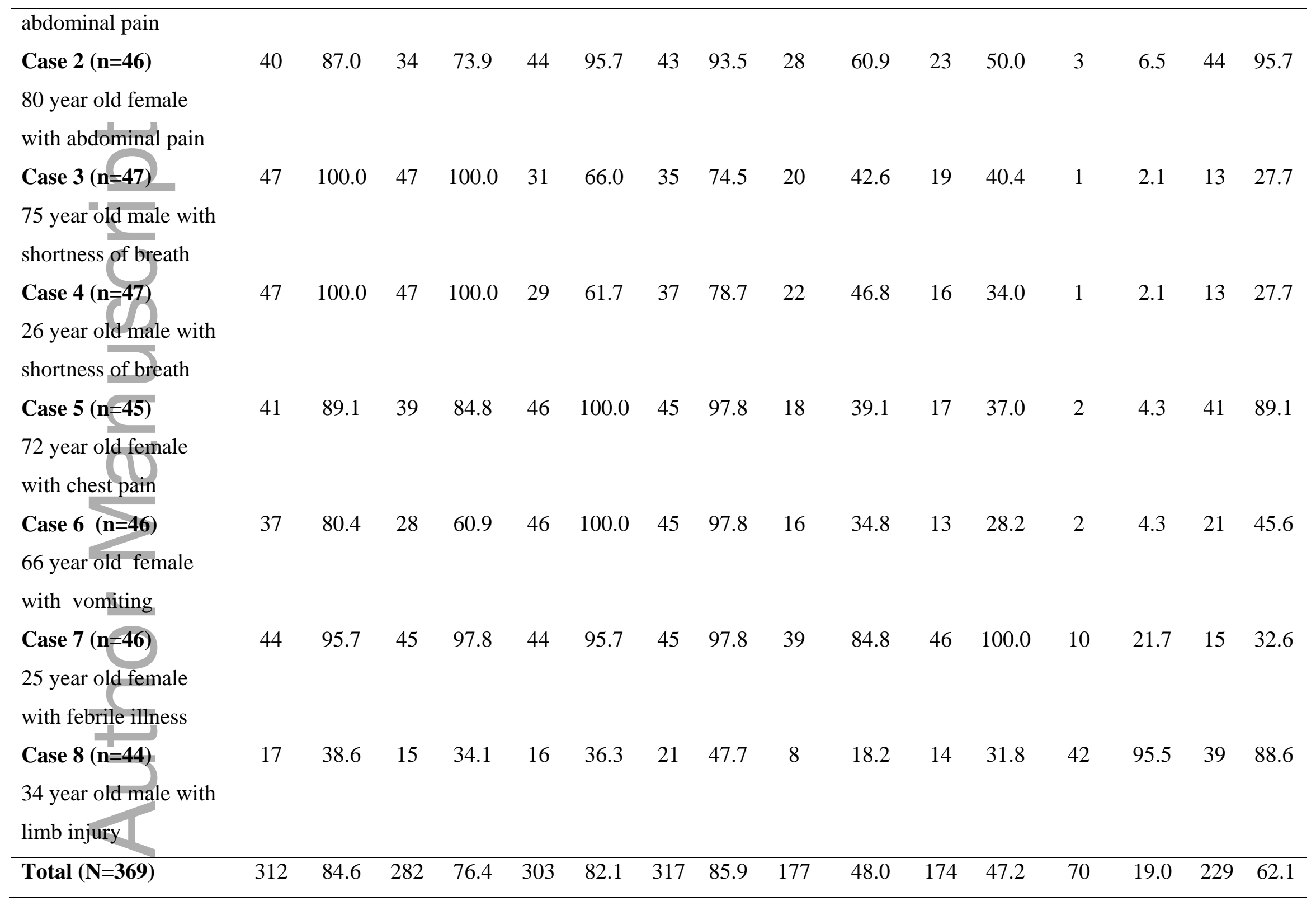

This article is protected by copyright. All rights reserved 


\section{University Library}

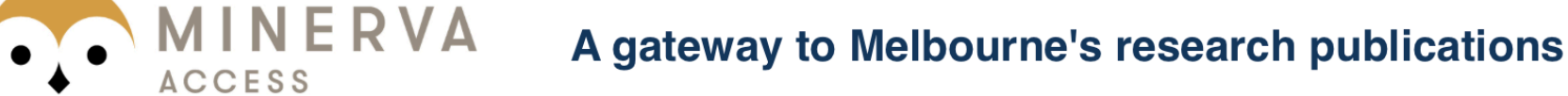

Minerva Access is the Institutional Repository of The University of Melbourne

Author/s:

Lambe, K;Currey, J;Considine, J

Title:

Emergency nurses' decisions regarding frequency and nature of vital sign assessment.

Date:

2017-07

Citation:

Lambe, K., Currey, J. \& Considine, J. (2017). Emergency nurses' decisions regarding frequency and nature of vital sign assessment. J Clin Nurs, 26 (13-14), pp.1949-1959. https://doi.org/10.1111/jocn. 13597.

Persistent Link:

http://hdl.handle.net/11343/292677 